\title{
Virtualidade e Computação: de Concepções Filosóficas a Práticas Educativas
}

Virtuality and Computation: from Philosophical Conceptions to Educational Practices

\author{
Cilmar Santos de Castro ${ }^{1}$ \\ Palavras-chave: \\ Resumo: \\ Este artigo apresenta um estudo conceitual, oriundo de dissertação (Mes- \\ Virtual \\ trado em Educação) do autor, sobre o constructo do Virtual, que par- \\ te da fundamentação filosófica até alcançar sua incorporação em ações \\ Ensino \\ educativas. O referencial teórico utilizado é pautado principalmente nas \\ proposições do filósofo francês Pierre Lévy, extraindo elementos que \\ possibilitem um entendimento mais profundo do que é o Virtual, em sua \\ Tecnologias \\ Educacionais \\ essência humana, o que vem a favorecer uma melhor apropriação de seu \\ potencial. A partir da análise bibliográfica da obra de Lévy, o estudo gera, \\ como principal resultado, o estabelecimento de quatro referenciais para \\ identificação do conceito de Virtual, em sua ampla e complexa conota- \\ ção humanista/tecnológica (ontogênese), o que favorece sua aplicação \\ em diversos contextos educativos. Desta forma, permite que o conceito \\ de virtualidade seja percebido além do mero artefato computacional, mas \\ que com este amplia os horizontes cognitivos dos aprendentes do nosso \\ mundo tecnológico.
}

Artigo

Original

Original

Paper

\section{Abstract}

This article presents a conceptual study performed in my dissertation (MA in Education), about the construct of the Virtual, which commences in the philosophical foundations and goes as far as the incorporation of educational activities. The theoretical framework is guided mainly by the propositions of French philosopher Pierre Lévy, especially when it comes to the elements that enable a deeper understanding of what is Virtual in human essence, that promotes an improved ownership of potentials. From the literature review of Lévy's work, the study generates as main results the establishment of four references to identify the concept of the Virtual, in the vast and complex human-technological connotation (ontogenesis), which favors its application in different educational contexts. Hence, the concept of virtuality allows itself to be perceived beyond a mere computational artefact, as it broadens the learners' cognitive horizons of our technological world.
\end{abstract}

Key words:

Virtual

Teaching

Educational

Technologies
Recebido em $10 / 2011$

Aprovado em $03 / 2012$ 


\section{Introdução}

As mudanças nas estruturas sociais, na economia globalizada, no ferramental tecnológico, nas concepções do mercado de trabalho, nos valores humanos, forçam o ato de repensar o papel do Homem frente a tais desafios. E também a criar estratégias para o convívio neste inédito momento da civilização, quando a informação e o conhecimento tornamse os bens mais preciosos, bens estes que possuem sua essência virtual e que são potencializados por ferramentas virtuais. Mas até que ponto realmente entendemos com clareza o que é o virtual ?

Certamente nunca antes as mudanças das técnicas, da economia e dos costumes foram tão rápidas e desestabilizantes. Ora, a virtualização constitui justamente a essência, ou a ponta fina, da mutação em curso. Enquanto tal, a virtualização não é nem boa, nem má, nem neutra. Ela se apresenta como o movimento mesmo do "devir outro" ou heterogênese - do humano. Antes de temê-la, condená-la ou lançar-se às cegas a ela, proponho que se faça o esforço de apreender, de pensar, de compreender em toda sua amplitude a virtualização. (LÉVY, 1996, p. 11)

A preparação para os novos tempos exige a plena compreensão dos elementos que o constituem e são necessários para chegar aonde se deseja. A partir de um cenário extremante dinâmico, instável, complexo e de poucas certezas, a humanidade busca um real e amplo sentido de educação. A questão da técnica fica cada vez mais presente.

O cúmulo da cegueira é atingido quando as antigas técnicas são declaradas culturais e impregnadas de valores, enquanto que as novas são denunciadas como bárbaras e contrárias à vida. Alguém que condena a informática não pensaria nunca em criticar a impressão e menos ainda a escrita. Isto porque a impressão e a escrita (que são técnicas!) o constituem em demasia para que ele pense em apontá-las como estrangeiras. Não percebe que sua maneira de pensar, de comunicar-se com seus semelhantes, e mesmo de acreditar em Deus [...] são condicionadas por processos materiais. (LÉVY, 1993, p. 15)

Enxergar além das superfícies das interfaces digitais, dos softwares e hardwares, cada vez mais presentes no cotidiano, requer um olhar mais profundo, sistêmico e fundamentado numa concepção filosófica de virtual que antecede a qualquer tecnologia de computação, mas que com ela se mescla e se expande.

O presente estudo trata exatamente do aprofundamento do conceito de virtual, a partir um enfoque filosófico, visando estabelecer vínculos com as práticas educativas. Constitui uma pesquisa descritiva teórica, cuja metodologia adotada utiliza a pesquisa bibliográfica, tendo como principal referencial a obra de Pierre Lévy expressa em alguns de seus livros (LÉVY, 1993, 1996, 1999, 2001, 2010). A concepção desta pesquisa teve seus primeiros insights na monografia $O$ Ensino de Informática na FOA: Contextualização da Formação Acadêmica, Desafios e Rumos (CASTRO, 2000) e foi estruturada na dissertação de Mestrado em Educação $O$ Virtual e o Ensino de Informática: Novas Configurações das Ecologias Cognitivas (CASTRO, 2001), aqui atualizada e apresentada parcialmente na forma de artigo inédito. Tem como principais objetivos:

1) ampliar o entendimento sobre o conceito de virtual, indo além de sua concepção estritamente tecnológica e valorizando seu sentido filosófico e humano.

2) propor referenciais para que auxiliam a identificação do virtual.

3) estabelecer ligações do virtual com a aplicabilidade deste em práticas de ensino.

A investigação do virtual proporciona o questionamento da relação com: o conhecimento, a memória, os dispositivos técnicos e com a própria inteligência, sendo, portanto, de substancial relevância para fins educacionais.

\section{Muitas Virtualidades}

O termo virtual tem alcançado popularidade nos dias de hoje, principalmente a partir da massificação do uso da informática em que este se assemelha ao digital, transmitindo 
uma ideia de modernidade e tecnologia. Mas, com termo polissêmico e presente em diferentes contextos, o virtual pode ser interpretado como projeção, o que existe em potência e não em ato, desprovido de existência, ou até mesmo, em sentido popular, sinônimo de falsidade ou ilusão. Muitas expressões são veiculadas: imagem virtual, realidade virtual, sexo virtual, comunidade virtual, ensino virtual, tantas virtualidades a debater, espalhando-se em patamares técnico, de senso comum e filosófico.

Diante de diversas acepções, surge a necessidade do estabelecimento de critérios e definições. Afinal de contas, o que é o virtual? Tal indagação serviu de título de livro e temática para o filósofo francês Pierre Lévy (1996) e ainda foi discutido em outras de suas obras $(1993,1999,2001,2010)$. A discussão acerca do virtual mobilizou, no século XX, o pensamento de diversos filósofos, como Gilles Deleuze, Felix Guattari, Henri Bergson, Michel Serres e principalmente Pierre Lévy - sendo este o que mais se deteve a analisar os processos de virtualização e suas implicações nos planos filosóficos (a conceituação do virtual), antropológico (a relação entre o virtual e o processo de hominização) e sócio-político (a compreensão e a atuação na dinâmica de transformações da sociedade), constituindo a cibercultura que temos em constante construção. As ideias de LÉVY propiciaram influências no Brasil, impulsionando trabalhos de pesquisadores como LEMOS (2001, 2010), MARTINS e SILVA (2000, 2004), PELLANDA e PELLANDA (2000), CASTRO (2001) e RUDIGER (2007).

A origem etimológica do termo virtual vem do latim medieval virtuallis, derivado por sua vez de virtus, significando força, potência. Uma importante diferenciação a ser feita, num sentido rigorosamente filosófico, é que o virtual não se opõe ao real, mas sim ao conceito de atual. LÉVY considera o virtual como um complexo problemático, um conjunto de vetores de forças, tensões, que chama uma ação de atualização para sua resolução - o que implica sempre em uma ação criativa, nunca determinada, a priori. Argumenta que os processos de virtualização são muito anteriores ao fenômeno das tecnologias digitais de informação e que estão intrinsecamente ligados ao desenvolvimento do Homem, desde os primórdios da sua existência. Nesse sentido, a linguagem e a técnica são os dois principais vetores de virtualização. Passado, presente e futuro da evolução humana estão envoltos pelo virtual.

\section{Os Quatros Modos de Ser}

Para um melhor entendimento da significação dos conceitos filosóficos propostos, faz-se necessária a distinção entre os pares possível-real e virtual-atual, propostos por LÉVY. A diferenciação entre estes constructos é a base para sua compreensão. "O possível é exatamente como o real: só lhe falta a existência.[...] A realização de um possível não é uma criação, no sentido pleno do termo, pois a criação implica também a produção inovadora de uma ideia ou uma forma." (LÉVY, 1996, p. 16). Possível e real se encontram nos campos das probabilidades, da seleção, da ocorrência de um estado pré-definido enquanto virtual e atual têm um sentido forte de problematização, interpretação e criação.

Já o virtual não se opõe ao real, mas sim ao atual. Contrariamente ao possível, estático e já constituído, o virtual é como o complexo problemático, o nó de tendências ou de forças que acompanha uma situação, um acontecimento, um objeto ou uma entidade qualquer, e que chama um processo de resolução: a atualização. (op. cit, p. 16)

No campo da linguagem, uma palavra é um ente virtual. Enquanto expressão virtual, pertence a todos e a ninguém. Destituída de matéria, traz consigo uma série de valores, imagens e significações (muitas delas até contraditórias) que permitem a resolução de problemas - por exemplo, comunicar uma ideia. Mas a solução, quer dizer, sua atualização é que estabelece valor próprio. A ação de trazer à tona a palavra, com sua entonação e temporalidade, equaliza intenções e contextos, abrindo as portas para o sentido. Ainda que uma palavra (e não sua enunciação) não possa ser fixada em qualquer coordenada espaço-temporal, o virtual existe, como uma palavra existe de fato. "O virtual existe sem estar presente" (LÉVY, 1999, p. 48) e permite indefinidas atualizações. 
No ambiente de informática, a execução de um programa de computador, por sua determinação puramente lógica, estabelecida, tem a ver como o par possível-real. Possível, porque representa um conjunto finito - ainda que imenso - de ações totalmente préconcebidas, possui resultados previsíveis em função de suas entradas (parâmetros), é logicamente fechado, sem brechas para a invenção, para o romper endógeno. Real, porque significa a efetivação do resultado, baseada na seleção de possibilidades, sem a intervenção criadora da subjetividade humana. Simplesmente se concretiza no resultado, migrando do limbo para o tempo presente.

Já a interação entre humanos e sistemas informáticos, com seus obstáculos e conquistas, caracteriza o par virtual-atual. Virtual por engendrar uma problemática de manipulação, de domínio, aberta às interpretações, subjetividades, com toda uma fenomenologia que compõe esta relação. Atual, pois sua efetivação representa uma solução particular, inédita e criativa, que atende à problemática original, específica configuração de elementos. Uma resposta que não estava contida em lugar algum, que se cria na própria interação.

Portanto, a mera digitalização da informação (codificação para o ambiente informático, em um suporte digital) não caracteriza uma virtualização no sentido filosófico, mas apenas no sentido técnico do termo. O ferramental tecnológico computacional só demonstra a virtualidade ampla de LÉVY quando visto sob a perspectiva de instrumento de operacionalização de problemáticas humanas.

Os modos de ser possível, real, virtual e atual são assim apresentados visando uma distinção conceitual, para fins de identificação mais didática. Porém, estão presentes de forma inextrincável na maioria dos fenômenos. "Toda situação viva faz funcionar uma espécie de motor ontológico a quatro tempos e portanto jamais deve ser "guardada" em bloco num dos quatro compartimentos" (LÉVY, 1996, p. 142).

Para exemplificar, serão considerados, dentro dessas perspectivas, dois elementos: o computador e aula. Como possível, o computador é um projeto definido, programado para cumprir suas funções, seguir fluxos lógicos; como real é a resposta precisa, operador calculista que se manifesta em saídas inteligíveis, objeto que tem volume e peso, consome energia; como virtual, é o desafio de ser dominado e de dominar o universo que este engloba, de solucionar problemáticas complexas, de provocar o novo; como atual, é a satisfação de pequenas conquistas, simulação sensorial, construção de modelos e elaboração coletiva. Usando o mesmo tipo de análise, a aula pode ser concebida como possível, enquanto disposição de uma disciplina e grade curricular, agendamento de evento datado, requisito de aprovação; como real, execução de um trabalho, cumprimento dos cinquenta minutos, transmissão de massa de informação; como virtual, oportunidade de crescimento, campo aberto de conhecimentos, valoração de sinergias; como atual, vivências de aprendizagem, trilha contínua, revelação do mundo. Percebe-se daí que a elevação à condição de virtual demanda o uso de uma abordagem crítica e o estabelecimento de referenciais que o sustentem como tal.

\section{Ontogênese do Virtual}

Frente à abrangência e tenuidade que o virtual enseja, como identificá-lo de forma consistente? Claro que sua identidade é, em primeiro lugar, percebida através da análise crítica e da sensibilidade, mas seria de grande valia que fossem estabelecidos alguns critérios ou propriedades fundamentais para melhor delineá-lo. A proposta aqui é extrair da obra de LÉVY as características marcantes que fazem que o virtual se constitua e ecloda, como integrante da dimensão humana e não no sentido da virtualidade estritamente técnica (oportunizada pela digitalização). Uma descrição da ontogênese do virtual.

Ontogênese porque visa explicitar seu foco essencial, onde onto significa relativo ao ser, e gênese representa o nascimento, geração, origem. Uma ontogênese do virtual representa o nascimento do virtual no Homem, ao invés da virtualidade parcial das máquinas. São as características que fazem o virtual emergir e que o tornam parte indissociável da natureza humana. Para fins de sistematização do conceito, são sugeridos quatro referenciais principais: Desterritorialização, Efeito Moebius, Subjetividade, e Problematização / Criação. Cada um deles oferece novas pistas acerca da virtualidade, o que permite reflexões mais direcionadas sobre o tema. 


\subsection{Desterritorialização}

A desterritorialização é a dissociação a um território fixo, fazendo fluir livremente ao encontro de outros campos de sentido. A informação e o conhecimento são entes desterritorializados, pois são desprendidos do aqui e agora. Não estão presos a um suporte físico único, são voláteis, possuem alta fluidez, navegam em diferentes suportes, no cérebro humano, na imprensa ou no computador.

Uma exemplificação desse referencial: com a modernidade, o escritório passou a usar computadores para o gerenciamento digital da informação. O documento agora é arquivado sob a forma de números, digitalizado, representa conjuntos de bytes inscritos em uma superfície magnética em um dispositivo de armazenamento. Aproveita da platicidade, da capacidade de manipulação que a computação permite - pode ser exibido em diversos formatos, alterado, ordenado por vários campos, duplicado facilmente por segurança (backup). Instalado em um equipamento servidor, pode ser compartilhado e manipulado, em um mesmo instante, pelos funcionários do escritório ou da matriz, a quilômetros de distância. Pode ser exibido no celular, na televisão, em tablets ou outros dispositivos, com a crescente convergência digital que já vivenciamos (JENKINS, 2008). Ao ser usado, não se decompõe nem vira monopólio.

O documento tornou-se um ente virtual (em sua acepção ainda técnica, computacional), não é mais o papel, é a informação. Como TOFFLER afirmou no início da década de 80 , o consumo e o compartilhamento de uma informação não é destrutivo nem monopolista, pois ela é generativa e sua manipulação múltipla amplia a possibilidade de criação de novas informações (TOFFLER, 1983, p. 32). Em decorrência disto, LÉVY sugere a emergência de uma nova economia das abundâncias ao invés da economia de raridade que vigora, baseada no consumo destrutivo e na apropriação exclusiva.

Uma comunidade virtual existe, mas não está amarrada a uma coordenada geográfica, reunindo seus membros pela conjunção de interesses (o que a torna mais autêntica) e não pela proximidade física. A própria designação de membro, originária de uma ligação física forte (como membros de um corpo) ganha outra fluidez. Os contatos se estabelecem sob a forma de textos, troca de mensagens e imagens, compartilhamento de músicas, vídeoconferência e tantos outros. É importante destacar que a desterritorialização não deve ser entendida como uma ausência ou extinção de territórios, mas sim, como a possibilidade de deslocamentos entre espaços. A desterritorialização de hoje deve ser encarada e construída como a possibilidade de ir além, de fluir entre campos, de criar caminhos, estabelecer links, subjetividades e novos territórios.

\subsection{Efeito Moebius}

O efeito Moebius é uma designação originária da iniciativa do matemático e astrônomo August Ferdinand Möbius em demonstrar a fragilidade de raciocínios lineares e a ocorrência das translações entre interioridade e exterioridade. Ele pegou uma fita e juntou suas pontas, mas invertendo uma delas em 180 graus antes de colá-las. A seguir, conseguiu percorrer com a ponta de um lápis riscando a superfície da fita, sem encontrar obstáculos, até retornar ao início do risco. Tal forma ficou conhecida como Anel de Moebius. Com isso, demonstrou como a passagem do interior para o exterior (e vice versa) pode acontecer de forma transparente, despercebida e como a pretensa exatidão da razão linear, das formas euclidianas, da mensuração absoluta pode ser ludibriada. Depois, pegou uma tesoura e cortou a fita circular seguindo o risco, de fora a fora, sem, no entanto conseguir separá-las, pois formou dois círculos entrelaçados, simulando o símbolo matemático do infinito.

Apoiado pela desterritorialização que possui, o virtual engendra passagens entre interior e exterior. Até que ponto a cognição, as ferramentas, a inteligência, as informações, os signos e as memórias são elementos internos ou externos? Ao usar um computador, estamos transladando fluxos de informações entre cérebros e máquinas. KURZWEIL (2007) argumento que com o crescimento do poder de armazenamento e de cálculo, a computação promete avanços que tonarão as máquinas cada vez mais interpretativas, incorporando sofisticada inteligência computacional e representações cada vez mais humanas. 
No contexto do Ensino a Distância (EaD), a utilização de ambientes virtuais de aprendizagem (AVA) requer todo um cuidado pedagógico, apoio de designer instrucional e equipe multidisciplinar para construir um espaço que propicie vivências de aprendizado autênticas, valorizando a cooperação e interação de seus participantes (COLL e MONEREO, 2010), indo além do mero download de apostilas. É fundamental fazer com que o aprendente, mesmo em seu lar, sentado diante de uma tela de computador, se sinta dentro da Instituição de Ensino, da turma e do conteúdo que este busca. E assim consiga transformar o fluxo de informações em verdadeiro conhecimento. "De fato, com o aumento das conexões, não é tanto o espaço que se retrai, mas o humano que se amplia." (LÉVY, 2001, p.48).

\subsection{Subjetividade}

Diferenciando a virtualidade estritamente técnica da computação (baseada na digitalização, na lógica binária e objetividade das máquinas) do virtual de essência humana, encontra-se mais um item: a subjetividade. A relação entre virtual e subjetividade está presente no discurso de LÉVY, ao fazer referência à escrita e à leitura. Muito além do registro da fala ou normatização da comunicação, a escrita propicia a criação de um universo semântico em expansão, enquanto a leitura, mais do que ato de tradução de uma codificação formal, é a celebração da interpretação, festa hermenêutica de interconexão do sentido. "O virtual só eclode com a entrada da subjetividade humana no circuito, quando num mesmo movimento surgem a indeterminação do sentido e a propensão do texto a significar, tensão que uma atualização, ou seja, uma interpretação, resolverá na leitura." (LÉVY, 1996, p. 40).

A informática cria um novo ambiente uma nova ecologia cognitiva - de relações entre subjetividade e conhecimento. Sobre a interface homem-máquina como um campo de agenciamentos cognitivos, a professora Virgínia Kastrup considera:

A interface homem-máquina opera no nível onde o atual guarda a dimensão virtual. É nesta franja, nesta borda de circulação de fluxos que se revela a po- tência de virtualização da cognição ou da subjetividade que o manejo do dispositivo técnico comporta. É também no plano das interfaces existentes entre o homem e os diferentes dispositivos técnicos que são criadas diferentes formas de conhecer. (KASTRUP in PELLANDA e PELLANDA, 2000, p.42)

A expansão de redes sociais como Orkut e Facebook demonstram como a "infovia" está repleta de sentimentos, curiosidades, emoções e subjetividades. Cabe aos educadores, então, canalizar as motivações e energias presentes nos usuários das tecnologias informáticas para o uso direcionado na aquisição de conhecimentos, na multiplicação das possibilidades de aprendizagem colaborativa, na formação de consciência crítica e na expansão da subjetividade.

\subsection{Problematização / Criação}

Em função de seu caráter desterritorializado e de sua gênese subjetiva, o virtual apresenta-se como mobilizador de problematização e de criação. "Virtualizar uma entidade qualquer consiste em descobrir uma questão geral à qual ela se relaciona, em fazer mutar a identidade em direção a essa interrogação" [...] (LÉVY, 1996, p. 40). Ao virtualizar uma comunidade, uma competência ou uma aula, definem-se questionamentos onde ocorre o deslocamento para interrogações do tipo: como estabelecer contatos e trocar experiências com pessoas interessadas em temas afins? Como registrar, transmitir e fazer incorporar uma competência? Como sistematizar (sem limitar) a exposição e favorecer a compreensão sobre um conteúdo? Esses exemplos lidam com algumas opções, dentre as inúmeras indagações que se desdobram a partir do complexo problemático que constitui o virtual. Se o contato em uma comunidade, a transmissão de uma competência e a execução de uma aula fossem elementos desprovidos de problemática - e de respectiva criação, como forma de solução - seriam meramente uma seleção entre possíveis pré-concebidos, materializados no real, sem a presença da subjetividade humana e de natureza restritiva; estariam presos ao território do aqui e agora, não seriam virtuais.

Virtualizar é problematizar, a fim de criar soluções inéditas, particularizadas para o con- 
texto abrangido - uma atualização que responde ao virtual. "Problemático por essência, o virtual é como uma situação subjetiva, uma configuração dinâmica de tendências, de forças, de finalidades e de coerções que uma atualização resolve. A atualização é um acontecimento, no sentido forte da palavra". (op. cit., p. 137). O professor André Lemos, que desenvolve trabalhos sobre cibercultura e arte na Faculdade de Comunicação da Universidade Federal da Bahia, assim expõe as proposições de LÉVY, no que diz respeito à problematização inerente à ação virtualizante:

Virtualização revela a desterritorialização, uma problematização do "aqui e agora", para um "além-da-qui". A virtualização é sempre uma problematização complexa do atual. Virtualizar é questionar. Ao escrever este artigo, atualizo diversas questões sobre a arte na era eletrônica. $\mathrm{O}$ leitor, ao tomar contato com este texto, virtualiza-o, na medida em que questiona o que está sendo dito, remete a referências próprias e individuais. (LEMOS in MARTINS e SILVA, 2000, p.229)

Este posicionamento, em um primeiro momento, parece contradizer o exposto por LÉVY, que trata inicialmente a escrita como virtualização da memória e a leitura como atualização do texto (LÉVY, 1996, p.35-38). Porém, o que LEMOS e LÉVY colocam são dois lados de uma mesma moeda; estão ambos na mesma direção, apenas alternam os sentidos do tráfego de virtual para atual e atual para virtual, num processo de sustentação mútua destes conceitos. O próprio LÉVY ressalta que "[a atualização é] uma produção de qualidades novas, uma transformação das ideias, um verdadeiro devir que alimenta de volta o virtual" (op. cit., p.17). Por essa ótica, o processo de escrita tanto pode ser visto como uma virtualização, por exteriorizar questões e sentimentos, quanto ser analisado como uma atualização, por ofertar propostas e soluções individualizadas para uma problemática. Virtual e atual, problemática e criação se impulsionam e se entrecruzam, revelando múltiplas passagens como em um Anel de Moebius.

\section{Oralidade, Escrita e Informática}

As formas de manifestação do virtual guardam direta relação com os regimes cognitivos vigentes, com suas técnicas de comunicação e ferramentas. Em Tecnologias da Inteligência (LÉVY, 1993) são explorados os seguintes regimes: a oralidade, a escrita e a informática. Ao analisá-los, LÉVY destaca a importância das linguagens como um dos principais vetores de virtualização - junto ao da técnica - que constituíram o Homem, abordados posteriormente em O que é o virtual ? (LÉVY, 1996).

A oralidade primária remete ao papel da palavra antes da adoção da escrita, enquanto a oralidade secundária representa a função da palavra em complementaridade ao exercício da escrita, como se conhece hoje. Numa sociedade oral primária, a cultura e a inteligência estão normalmente relacionadas à capacidade de memorização, ao acúmulo de saberes, à audição e à capacidade de argumentação. Todo conhecimento necessita de ser retomado, repetido em voz alta, sob pena de desaparecer pela ação do tempo. A cultura e o saber são transmitidos sob as formas de histórias, tradições, mitos, costumes e rituais, promovendo a contextualização dos conhecimentos em função da proximidade do sujeito que anuncia e cristaliza tais componentes da memória coletiva.

A escrita apresenta-se como regime cognitivo em que se torna possível a sistematização formal dos saberes, assim como o despreendimento do contexto no qual foram produzidos, valorizando assim novas técnicas mais apuradas de registro e interpretação dos fatos. A sequencialidade, a exteriorização, a busca de universalidade e a abstração são características valorizadas pela cultura escrita, influenciando e ampliando o pensamento e alterando a própria oralidade. A virtualização da memória através do texto possibilitou o vasto armazenamento e propagação dos conhecimentos e o aperfeiçoamento da análise teórica.

A invenção de Gutenberg propiciou um salto qualitativo e quantitativo para a escrita. A imprensa possibilitou a socialização da cultura do texto, antes enclausurada nos manuscritos e nas elites intelectuais. Novos espaços e velocidades foram criados, dinamizando a relação com 
o conhecimento. Estudiosos como Walter Ong e Elisabeth Eisenstein descreveram como as técnicas de impressão mecânica exerceram influência sobre o desenvolvimento científico e cultural, principalmente a partir do século XVI. O progresso da humanidade caminhou e continua caminhando fortemente atrelado a esta técnica.

Com a instauração da informática como um novo regime cognitivo, a escrita ganha outras nuances, temporalidades e fins. Não mais estático, o suporte digital do texto abre dimensões inéditas. Surge o hipertexto, rompendo a linearidade da leitura, permitindo saltos para outros textos, representações e temáticas, navegando em redes. O grande volume de dados a serem absorvidos (processados) deslocam e apressam a escrita e a leitura para um enfoque mais operacional do que contemplativo, o que pode caracterizar um perigo em potencial à análise crítica. Em contrapartida, a informática amplia a capacidade de abstração e as possibilidades de interagir com fenômenos diversos, onde a simulação computacional cria "um conhecimento por simulação que os epistemologistas ainda não inventariaram" (LÉVY, 1993, p. 7). A Inteligência Artificial começa a mostrar sua face mais humana, afastando-se do estereótipo de dominadora, pela proposição ímpia de gerar máquinas mais inteligentes que os homens, para alcançar um status de ferramenta de auxílio à atividade produtiva, já disponibilizando produtos interessantes (KURZWEIL, 2007), como na área de linguística, os softwares de reconhecimento de fala que tendem a revolucionar a interação com computadores e demais dispositivos eletrônicos, tornando mais natural esta interface.

A crença no alto potencial de evolução da aprendizagem através da emergência das linguagens não faz com que LÉVY omita o desafio de adequação do ser humano, com seu ritmo biológico limitado, ao rápido desenvolvimento cultural e técnico. Longe de ser uma simples questão de recondicionamento, o sincronismo desejado passa pela plena apropriação destas novas linguagens, para que sejam estabelecidas relações autênticas (ao invés de impostas) e conscientes (ao invés de alienantes), que proporcionem discernimento e autonomia, sem a angústia de estar sendo afogado pelo dilúvio de informações.
Diante da importância do momento atual e da irreversibilidade (histórica e não determinística) do desenvolvimento da informática, a cegueira do ceticismo e a paralisia da perplexidade não fornecem bases suficientes para a reestruturação do projeto de humanidade. É preciso viver a mudança para mudar o modo de vida.

\section{Virtualidade e Educação}

Após a explanação sobre o conceito de virtualidade (os quatro de ser), de suas características essenciais (ontogênese), da exposição acerca dos regimes cognitivos (oralidade, escrita e informática), cabem aqui algumas questões: qual a relação entre a educação e o virtual? Quais as convergências e os desafios entre tais processos? Como canalizar a virtualidade como elemento educacional? Respostas complexas, que não estão prontas, merecem ser constantemente atualizadas.

Em primeiro lugar, vale destacar que não há simplicidade no virtual. Como campo problemático, produzido via subjetividade humana, desterritorializado e de múltiplas passagens (efeito Moebius), a ação virtualizante deve ser fruto de uma profunda reflexão, a fim de atingir sua aplicação eficaz. Do contrário, há o perigo da utilização do virtual sob a perspectiva exclusivamente instrumental e desprovida de um efetivo desenvolvimento cognitivo que leve à resolução de problemas através da criação - atualização.

O uso do ferramental tecnológico só se justifica, em termos educacionais, quando agrega outros valores e amplia a capacidade de aprendizagem e de produção de sentido. Aprender a operar um processador de textos, por si só, não implica em um crescimento intelectual que propicie uma maior capacitação para enfrentar as dificuldades da produção e interpretação de textos, assim como aprender a usar uma máquina de escrever mecânica não faz do datilógrafo mais inteligente ou competente nestes quesitos. Somente a partir do momento em que o domínio operacional do dispositivo é incorporado ao sujeito e este consegue romper com o uso mecânico do objeto técnico para atingir o patamar de produção inventiva, quando acionar um comando 
abre "janelas" inéditas de soluções que permitem vislumbrar novos horizontes cognitivos para o saudável embate diante do texto, é que se usufrui plenamente do virtual.

Percebe-se nesta exemplificação que a caracterização do processo de virtualização é bastante tênue e depende mais da concepção e da proposta de ação do que propriamente dos instrumentos utilizados. É possível ser mais virtual com um lápis e uma folha de papel do que computadores e softwares de última geração usados de maneira inadequada. Tudo depende da perspectiva educacional que é impressa em cada ato.

O segundo ponto a ser verificado é a correspondência (e a necessidade de adequação) entre as características intrínsecas do virtual e alguns componentes essenciais do processo educacional, presentes em diversas teorias de aprendizagem (MOREIRA, 2011). Trabalhar o desenvolvimento da subjetividade, a problematização e a resolução criativa são objetivos educacionais e componentes genitores do virtual. A correlação entre tais preceitos é facilmente percebida, mas a implementação eficaz da ação educativa que produza a virtualidade em sua mais ampla acepção, de despreendimento do aqui e agora para uma elevação cognitiva e valorativa, é tarefa de maior nível de dificuldade. Requer o esforço de reavaliação e reformulação das práticas didáticas e a reflexão sobre a finalidade e os desdobramentos desejados a partir da aplicação dos conteúdos. É fazer com que o aprendiz enxergue além, pelas lentes do virtual.

O conhecimento, por sua vez, é o fruto de uma aprendizagem, ou seja, o resultado de uma virtualização da experiência imediata. Em sentido inverso, este conhecimento pode ser aplicado, ou melhor, atualizado em situações diferentes daquelas da aprendizagem inicial. Toda aplicação efetiva de um saber é uma resolução inventiva de um problema, uma pequena criação. (LÉVY, 1996, p. 58)

LÉVY e TENÓRIO concordam sobre a importância da questão da técnica nos dias atuais, em que as tecnologias informáticas são instrumentos fortemente relacionados com a cognição, e que o desvendamento dessas relações é uma das tarefas mais importantes da escola contemporânea afinada com as questões relevantes do nosso tempo (TENÓRIO, 1998, p. 202). As TIC (Tecnologias da Informação e da Comunicação) estão sendo espalhadas nas escolas e o Ensino a Distancia ganha espaço, ampliando a necessidade de aquisição de competências para ensinar e aprender em ambientes virtuais. "[...] não há dúvidas que a incorporação das TIC modifica e reestrutura as formas de pensar e de aprender e, consequentemente, deve modificar as formas de ensinar". (COLL e MONEREO, 2010, p.104).

Mas existem riscos ao tentar abarcar o virtual. Atenção redobrada é necessária para que uma proposta didática não se dilua na fluidez do conceito. Cabe aos educadores impedir que a desterritorialização se transforme em ausência e perda de referenciais, que a subjetividade converta-se em mero palpite ou impulso, que ao invés da problematização e da inovação surja a reificação que ergue barreiras e sonega a criação, que o efeito Moebius reduza-se a uma caótica navegação entre vazios internos e externos.

Portanto, se não for bem conduzida, a virtualização pode se configurar como um obstáculo à aprendizagem, assim como as tecnologias informáticas podem também padecer deste mal. Criar estratégias para encaminhar aprendizes ao eficiente manuseio das ferramentas de informática e de seus produtos virtualizados é promover a competência de superação das limitações, a valorização da autonomia cognitiva e da produção de conhecimento.

Diante da escola filosófica francesa atual, com muitos representantes contrários aos processos de informatização e globalização, LÉVY surge como expoente de uma nova postura, mais aberta e engajada com a busca da humanização através das técnicas, da descoberta de níveis mais elevados de colaboração e de desenvolvimento. Sem negar as imensas dificuldades a serem confrontadas, assume a crença de que é possível, através do ferramental disponível hoje, exercer a determinação de um modo de vida mais cooperativo, equânime e humano. Trata-se de uma decisão otimista.

Em geral, me consideram um otimista. Estão certos. Meu otimismo, contudo, não promete que a Internet resolverá, em um passe de mágica, todos os problemas culturais e sociais do planeta. Consiste apenas em reconhecer dois fatos. Em primeiro lugar, que o crescimento do ciberespaço resulta de um 
movimento internacional de jovens ávidos para experimentar, coletivamente, formas de comunicação diferentes daquelas que as mídias clássicas nos propõem. Em segundo lugar, que estamos vivendo a abertura de um novo espaço de comunicação, e cabe apenas a nós explorar as potencialidades mais positivas deste espaço nos planos econômico, político, cultural e humano. (LÉVY, 1999, p. 11)

Sempre que podemos produzir com voz livre (liberação do polo da emissão), nos organizar, conectar e produzir coisas coletivamente (o princípio da conexão), iremos, com certeza, produzir reconfigurações nas instituições culturais, no fazer político, no espaço público, na democracia. (LÉVY e LEMOS, 2010, p. 83).

Otimista como convém a todos que estão comprometidos com a Educação, que acreditam na melhoria do mundo através da construção de uma sociedade mais consciente, integrada e preparada para o futuro, procurando oferecer suas modestas contribuições. É preciso compreender, vivenciar e elaborar os novos tempos, para que a humanidade faça uma escolha inteligente diante do virtual.]

\section{Considerações Finais}

A fundamentação filosófica sobre o virtual é de suma importância para o entendimento do contexto atual, cada vez mais envolto por ele- mentos virtuais. $\mathrm{O}$ arsenal de dispositivos de informática deve ser compreendido, em primeiro lugar, como ferramental de operacionalização de problemáticas humanas, não estritamente computacionais. Armazenamento e cálculo são pilares da computação, mas devem ser transparentes para usuários em geral, que enxergam em suas telas não bits e algoritmos, mas informações e desafios a serem apropriados e transformados em conhecimentos, mesclando o que há de melhor entre homens e máquinas.

A proposição dos quatro referenciais da ontogênese do virtual (Desterritorialização, Efeito Moebius, Subjetividade e Problemática/ Criação) representa um esforço acadêmico (honesto e fundamentado) de contribuir para que a aplicação do conceito não se perca de seus objetivos fundamentais, servindo de orientação para melhores aplicações de práticas educativas, valorizando uma educação comprometida com a capacidade de compreensão e questionamento, seja qual for a ferramenta - de lápis e papel ao mais moderno computador.

Virtualidades favorecem o desenvolvimento cognitivo à medida que tornam o exercício da aprendizagem mais livre, acessível e modelável. $\mathrm{O}$ virtual estimula a abordagem da contraposição e de mesclas: concreto e abstrato, interior e exterior, problema e solução, o que implica no questionamento, na dúvida e na criação, saudável tríade na aquisição de conhecimentos. As diversas ligações entre as características do virtual e os objetivos educacionais formam um hipertexto a ser continuamente construído, questionado e aperfeiçoado. Onde nós somos nós de uma rede sem fim. 
8. Referências Bibliográficas

1. CASTRO, Cilmar Santos de. O Virtual e Ensino de Informática: Novas Configurações das Ecologias Cognitivas. 2001. Dissertação (Mestrado em Educação e Saúde) - UniFOA, Volta Redonda, 2001.

2. O Ensino de Informática na

FOA: Contextualização da Formação Acadêmica, Desafios e Rumos. 2000. Monografia (Formação de Docentes para o Ensino Superior) - Universidade Gama Filho, Volta Redonda, 2000.

3. COLL, César; MONEREO, Carles (org). Psicologia da Educação Virtual: Aprender e Ensinar com as Tecnologias da Informação e Comunicação. Porto Alegre: ArtMed, 2010.

4. JENKINS, Henry. Cultura da Convergência. São Paulo: Aleph, 2008.

5. KURZWEIL, Ray. A Era das Máquinas Espirituais. São Paulo: Aleph, 2007.

6. LEMOS, André; PALACIOS, Marcos. Janelas do Ciberespaço: Comunicação e Cibercultura. Porto Alegre: Sulina, 2001)

7. LÉVY, Pierre; LEMOS, André. O futuro da Internet: em Direção a uma Democracia Planetária. São Paulo: Paulus, 2010.

8. LÉVY, Pierre. A Conexão Planetária: o Mercado, o Ciberespaço, a Consciência. São Paulo: 34, 2001.

9. Cibercultura. São Paulo: 34, 1999.
10. O que é o Virtual ?. São Paulo: 34, 1996.

11. As Tecnologias da Inteligência: O Futuro do Pensamento na Era da Informática. São Paulo: 34, 1993.

12. MARTINS, Francisco Menezes; SILVA, Juremir Machado (orgs). A Genealogia do Virtual: Comunicação, Cultura e Tecnologias do Imaginário. Alegre: Sulina, 2004.

13. (orgs). Para navegar no

século XXI: Tecnologias do Imaginário e Cibercultura. Porto Alegre: Sulina / Edipucrs, 2000.

14. MOREIRA, Marco Antonio. Teorias de Aprendizagem. São Paulo: EPU, 2011.

15. PELLANDA, Nize Maria Campos; PELLANDA, Eduardo Campos. Ciberespaço: Um Hipertexto com Pierre Lévy. Porto Alegre: Artes e Ofícios, 2000.

16. RUDIGER, Francisco. Introdução às Teorias da Cibercultura: Tecnocracia, Humanismo e Crítica no Pensamento Contemporâneo. Porto Alegre: Sulina, 2007.

17. TENÓRIO, Robinson Moreira. Cérebros e Computadores: A complementaridade analógico-digital na informática e na educação. São Paulo: Escrituras Editora, 1998.

18. TOFFLER, Alvin. Previsões e Premissas. Rio de Janeiro: Record, 1983.
Endereço para Correspondência:

Cilmar Santos de Castro

cilmar.castro@ifrj.edu.br

Rua Capitão Mário Novais, 49

Barra do Piraí - RJ

CEP: 27123-110 